\title{
Power Quality Enhancement Using DSTATCOM in Industry Plants
}

Research Article

Atinkut Bayu

Department of Electrical and Computer Engineering, Debre Berhan University, Ethiopia

Received: September 22, 2020; Accepted: November 08, 2020

\begin{abstract}
This paper is focused on increasing the power quality of Unique Macaroni factory, located in Bahir Dar Town. Necessary data have been collected from the factory and the collected data are analysed. Based on the analysis of data, it is found that the factory working power factor is low and hovering around 0.7125 . Voltage variations are up to $9.09 \%$, average voltage unbalance is $2.2 \%$ and total harmonic distortion (THD) of load currents and voltage are $24.17 \%$ and $10.16 \%$, respectively. Harmonic components have existed in the power distribution system of the factory. Based on the analysis of power quality problem in the factory, distribution static compensator (DSTATCOM) and its control system have been designed to boost power quality of the factory and the results are obtained by generating simulations using Matlab software. It is observed from outputs of the Matlab simulations that DSTATCOM can improve the power quality of the factory. Generally, the shape of the waveform of load voltage and current is improved and THD level of load voltage is minimised to $1.55 \%$ and load current THD level is $7.09 \%$. The reactive power needed by the loads ( $442 \mathrm{kVAr}$ ) is almost provided by the DSTATCOM, so reactive power from source supply is very small such as $22 \mathrm{kVAr}$ so that the power factor of the source tends to unity.
\end{abstract}

Keywords: power quality • power quality problems • DSTATCOM • Matlab/Simulink

\section{Introduction}

Currently, day to day activities of human beings are highly dependent on electricity. Also, the power quality and uninterruptable power supply are important for the effective operation of the electrical appliances of the customers.

Power quality is well-defined by the level of supplied electrical energy that comforts the smooth function of the electrical appliances (IEEE, 2012). During the transmission of power, the variations in power quality are illustrated by the change of values of voltage, frequency and current from the nominal values resulting in faulty operation of electrical appliances used by the end-user. Today, electrical equipment of end-users consist of sensitive devices such as power electronic (non-linear devices) devices and these devices are greatly affected by various disturbances of the power supply system. Power quality problems associated disturbances such as harmonics, voltage sags, voltage swells, voltage fluctuations, voltage variations, flickers, etc. (Praveena et al., 2017; Sedaghati et al., 2013; Kaur, 2014) are increasing from time to time. On the other side, the client's electrical equipment has a negative impact on the power supply system.

Many problems are observed during the transmission of power to distribution network from the industrial feeder of Bahir Dar power distribution substation. Since the Unique Macaroni and Pasta flour plc factory is getting power from this power distribution system, it faces the following power quality problems: low power factor 0.7125 (lag), voltage variation, under voltage, voltage unbalance, waveform distortion especially harmonic distortion and frequent power interruption. These power quality problems have a negative influence on the productivity of Unique Macaroni and Pasta flour factory and the other customers. The drop in the voltage causes early failure of equipment and blackening of light bulbs, while excess voltage causes damage to electronic devices, burning of light bulbs, frequent power interruption and voltage fluctuation damaging sensitive power electronic devices. This paper is focused 
on the investigation and analysing of power quality problems, and design of mitigation technique for the Unique Macaroni and Pasta flour factory.

\subsection{Background}

Unique Macaroni and Pasta flour factory is a food processing factory in Bahir Dar City in Kebele 14 at the industrial village. The factory is manufacturing macaroni, flour and other related products for the community and it is getting the electrical power from the industrial feeder of the Bahir Dar distribution substation number two. The factory power distribution system consists of a service transformer with a capacity of $630 \mathrm{kVA}$. The total electrical load of the factory is about $572 \mathrm{kVA}$ which is calculated from the electrical parameter values of the total loads connected to the system. Two main sections of the company consume the major power. These sections are Macaroni section with a capacity of $432 \mathrm{kVA}$ and power factor of 0.784 , and Flour section with a capacity of $140 \mathrm{kVA}$ and power factor of 0.71306. The connected power grid system that supplies power to the factory is shown in Figure 1.

\section{Related Works}

The power quality issue is never-ending catchphrases at the power network. Both power suppliers and consumers of electric energy are highly concerned about the quality of electric power. Study of electrical power quality has been done by different researchers. Some works done in this area are summarised below.

The paper of Reid (2016) presented the important issues associated with power quality by summarising the key considerations, the applicable standards and areas where standards are being developed. The paper of Hossain et al. (2018) dealt on power questions in distribution power system concerned for renewable energy sources. Based on their investigation, transients have been found as the most severe power quality problems. The paper of Chauhan and Pandey (2014) discussed various power quality issues like voltage sag or dip, very short and long interruptions, voltage swells and explained the effects of the power quality problems to the electrical equipment. The paper of Shahewar et al. (2014) emphasized to voltage sags, transients, and waveform distortion and evaluated the effect of these problems on the system without and with the compensator devices. The study of Johnsoy and Hagren (2016) dealt with 'the issue of power quality in electrical systems'. The paper explains the cause and impact of electrical power disturbances. The paper of Priyanka et al. (2017) has analyzed 'role of DSTATCOM for increasing of power quality in power supply network'. The modelling distribution static compensator (DSTATCOM) has been studied and established for use in Simulink situation with the power system block sets. The paper of Paramar and Vora (2015) has conducted investigations on power quality improvement in distribution network using DSTATCOM. In the paper, the investigation on the role of DSTATCOM is carried out for advancing power excellence at supply networks via linear as well as nonlinear loads. This paper presents three load condition in which unbalanced source current and PCC voltage are balanced using DSTATCOM in unbalanced load condition. In balanced load condition total harmonic distortion (THD) is $41.66 \%$ without compensation and after reactive current compensation, it is 0.58\% using DSTATCOM. In the paper Nawaz and Hameed (2013), the study was conducted on minimization for power quality disturbances. The paper demonstrated that the voltage sags and swells can be mitigated by inserting DSTATCOM to the distribution system. In the paper Saradva et al. (2016), the authors have conducted a study on the Application of DSTATCOM to Control Power Flow in Distribution Line DSTATCOM. Their investigation showed that the reactive power demand by the load is almost covered by the DSTATCOM.

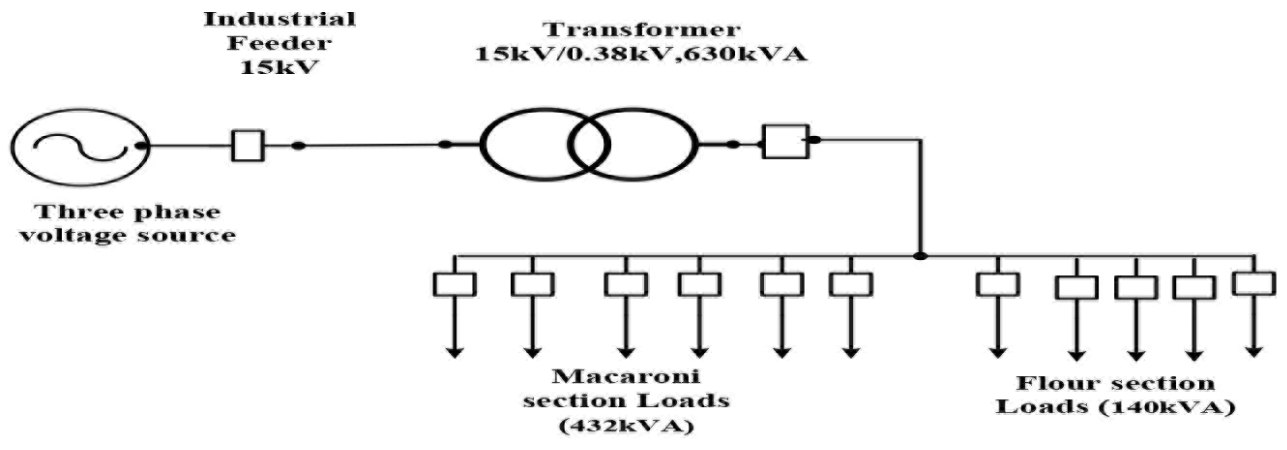

Fig. 1. One-line diagram of power grid or power distribution system of the factory. 


\section{System Modelling}

\subsection{Three-phase source modelling}

The power gird sinusoidal supply voltage source is $15,000 \mathrm{~V}$ at the terminal of the industrial feeder in the substation for the $230 \mathrm{kV} / 15 \mathrm{kV}$ step down transformer secondary side. The power delivered to the loads through the industrial feeder of the system is $10,530 \mathrm{kVA}$. Source resistance and inductance are calculated by using the following expressions (Shah and Parsa, 2016).

$$
\begin{aligned}
& R_{S}=\frac{V^{2}}{S * 10}=\frac{(15,000)^{2}}{\left(10,530 * 10^{3}\right) * 10}=2.14 \Omega \\
& L_{S}=\frac{V^{2}}{S * 2 * \Pi * F}=\frac{15,000^{2}}{10,530 * 10^{3} * 2 * \Pi * 50}=0.068 \mathrm{H}
\end{aligned}
$$

\subsection{Three-phase transformer modelling}

Rating of transformer is $630 \mathrm{kVA}, 15 \mathrm{kV} / 0.38 \mathrm{kV}, 50 \mathrm{~Hz}$ and $6 \%$ impedance. The per-unit resistance and inductance explained as:

$$
\begin{aligned}
& Z_{\text {base }}=R_{\text {base }}=X_{\text {base }}=\frac{\left(V_{n}\right)^{2}}{S_{\text {rated }}}=\frac{(15,000)^{2}}{630 * 10^{3}}=357.143 \Omega \\
& L_{\text {base }}=\frac{X_{\text {base }}}{2 \Pi F_{n}}=\frac{357.143}{2 * \Pi * 50}=1.137 \mathrm{H}
\end{aligned}
$$

Source impedance values in the winding one $R_{1}=2.14 \Omega$ and $L_{1}=0.068 \mathrm{H}$, based on the following equations; resistance and inductance in p.u for the transformer winding are computed.

$$
R_{1}=\frac{2.14 \Omega}{357.143 \Omega}=0.006 \mathrm{pu} \text { and } L_{1}=\frac{0.068 \mathrm{H}}{1.137 \mathrm{H}}=0.06 \mathrm{pu}
$$

\subsection{Modelling of the $60 \mathrm{~m}$ length}

The length between transformer and loads terminal is around $60 \mathrm{~m}$ and supply voltage is $380 \mathrm{~V}$ line to line and by considering the voltage drop in the line, secondary voltage of the transformer is given by the expression (Mehta, 2017):

$$
V_{\mathrm{sec}}=V_{\text {load }}+I R \cos \phi_{R}+I X_{L} \cos \phi_{R}
$$

The voltage regulation is given by:

$$
\% V R=\frac{V_{\text {sec }}-V_{\text {load }}}{V_{\text {load }}} * 100
$$

Total line power losses by considering the $5 \%$ of total power in the system, power losses in the feeder is

$$
P_{\text {losses }}=3 I^{2} R
$$

where $I$ - load current, $R$ - resistance of each conductor, $X_{L}$ - reactance, $V_{\text {load }}$ - load end voltage, $\phi_{R}$ - the system power factor and $V_{\mathrm{sec}}$ - secondary side of transformer voltage.

Load power is $630 \mathrm{kVA}$, load current is $957 \mathrm{~A}$ and power factor of the loads is 0.7125 . Total power loss due to the resistance of the lines is $P_{\text {losses }}=3 I^{2} R=0.05 * 630 * 0.7125=22.445 \mathrm{~kW}$, thus $R=0.0814 \Omega^{*} 0.06 / \mathrm{km}$ and the inductance value is calculated by using the Eq. (3), $L=0.004 \mathrm{H}$.

\subsection{Electrical loads}

The electrical equipment or devices used in the plant are three-phase squirrel induction motors, nonlinear loads such as adjustable speed drives, single-phase motors such as pumping motors and swimming machines, fluorescent 
lamps and computers. The maximum demand for the electrical load total apparent power in the system is $630 \mathrm{kVA}$, from the installed capacity of the transformer given the factory (Mehta, 2017; Sep 14). This power is calculated by using the load power factor 0.7125 , since total apparent power $(S)$ is the sum of active $(P)$ and reactive electrical power $(Q)$ used by the supply network.

$$
S^{2}=P^{2}+Q^{2}
$$

So, total active power is $P_{\text {tot }}=448 \mathrm{~kW}$ and total reactive power is $Q_{\text {tot }}=442 \mathrm{kVAr}$. Total system electrical loads can be classified in the following ways; General three-phase loads: $P=336 \mathrm{~kW}$ and $Q=334 \mathrm{kVAr}$. Nonlinear loads are represented by three-phase diode rectifier connected to a resistive and inductive loads. Nonlinear three-phase $P=101.33 \mathrm{~kW}$ and $Q=96.2 \mathrm{kVAr}$. Single-phase loads: $P=11.63 \mathrm{~kW}$ and $Q=11.05 \mathrm{kVAr}$,

Whereas $S_{\text {tot }}$ is total apparent power, $P_{\text {tot }}$ is total active power and $Q_{\text {tot }}$ is total reactive power of the network.

\section{The Modelling of Distribution Static Compensator}

Modelling of DSTATCOM consists of DC-Link capacitor, output filters, design of voltage source converters (VSCs) and Coupling transformer.

\subsection{Design of direct current-link capacitor}

DC link capacitor gives a constant DC voltage. The voltage from the DC-link must not vary for the suitable operation of the insulated gate bipolar transistor elements. Alternative current (AC) voltage is given by DSTATCOM via VSC. The DC-link capacitor size can affect the generated voltage magnitude as well as its wave shape and the function of the regulator, and then great care is necessary to size and select the DC-link capacitor value (Teke et al., 2015). Therefore, in this work, a proportional integrator regulator is applied to manage the output, DC voltage. The parameters of the PI controller are very important to produce a stable system. Based on the above study, the selection of capacitor voltage and the capacitance values of capacitor are calculated by using the following Eqs (7) and (8).

$$
\begin{aligned}
& V_{\text {dc.ref }}=\frac{2 \sqrt{2} V_{L}}{\sqrt{3} m_{a}}=\frac{2 \sqrt{2} * 380}{\sqrt{3} * 1}=620.507 \mathrm{~V} \\
& C_{\mathrm{dc}}=\frac{S_{n} \tau * 2}{\left(V_{\mathrm{DC}}\right)^{2}}=\frac{630 * 10^{3} * 0.004 * 2}{(620.915)^{2}}=0.01307 \mathrm{~F}
\end{aligned}
$$

where $V_{d c \text {.ref }}$ is the set point capacitor voltage, $V_{L}$ is three voltage of the network, $m$ is the modulation index, $C_{d c}$ is the capacitance value of capacitor, $S_{n}$ is apparent power rated of network and $\tau$ is a constant. The values are as follows: $V_{L}=380 \mathrm{~V}, \tau=4 \mathrm{~ms}, S_{n}=630 \mathrm{kVA}, m_{a}=1$. Locus DC voltage from the calculation and take some approximations as $700 \mathrm{~V}$ to minimise losses in the system, and this voltage source is the rectified DC voltage from the supply system and store in the capacitor. The DC-link capacitor value is calculated as $13,070 \mu \mathrm{F}$.

\subsection{Design of inverter output filter}

Design of inductors in the LCL filters based on the phase voltage drop across the inductors of the LCL filters must be $<10 \%$ of the phase voltage of the network (Xia et al., 2014).

$$
\omega L * I_{n}<10 \% \frac{U_{n}}{\sqrt{3}}
$$

Using this formula $L<0.07 \mathrm{mH}$, in our case $L=40 \mathrm{mH}$. Where $\omega$ is natural frequency, $314.16 \mathrm{rad} / \mathrm{sec}, I_{n}$ is Current per phases and $U_{n}$ is phase to ground voltage. The inductance values of the two sides are selected based on the power loss in the system is $<10 \%$ [20]. The inverter side inductor and the grid side inductor are related by some constant, $\alpha$ and by consideration of power loss in this paperwork the ratio of the inductors selected is $0.1 \mathrm{p} . u$ i.e., $L_{\text {grid }}=\alpha * L_{\text {inv }}, \alpha<1$, where $\alpha=0.1$. To achieve better productivity of DSTATCOM, reactive power used by the capacitor filter should not be $>5 \%$ of the system apparent power. 


$$
C \leq \frac{5 \% * S_{n}}{3 \omega\left(\frac{V_{n}}{\sqrt{3}}\right)^{2}}
$$

By substituting the values of the given parameter, the capacitor filter value is calculated as $C \leq 0.00207 \mathrm{~F}$. We estimated the value of the filter capacitor as $0.002 \mathrm{~F}$ which is connected to the inverter output sides.

\subsubsection{Damping resistance}

To increase the stability of the system, a small amount of damping resistance must be connected in series with capacitor filters and selection of this resistance must be very small to minimise the power losses and it depends on the quality factor (Tavakoli Bina and Pashajavid, 2009). The damping resistance at 60 quality factor is calculated using the following equation:

$$
R_{D}=\frac{2 \Pi F C}{60}=\frac{2 * \Pi * 50 * 0.002}{60}=0.01 \Omega
$$

\subsection{Coupling transformer}

A $700 \mathrm{~V} / 380 \mathrm{~V}$ coupling transformer ensures the synchronisation of the voltage produced by VSC and the grid voltage.

\subsection{Reactive power determination}

Reactive power given to the system by DSTATCOM is calculated as:

$$
\text { Reactive power }=\frac{\left(V_{d s t}-V_{s}\right) * V_{s}}{X}
$$

where $V_{d s t}$ is the output voltage of DISTATCOM, $V_{s}$ is the grid voltage and $X$ is the correspondent impedance between DSTATCOM and the grid system.

$$
Q=\frac{(700-380) * 380}{0.289}=420 \mathrm{kVAr} \text {, this is maximum reactive power compensation by DSTATCOM based on the }
$$

system requirement.

\subsection{VSC modelling}

The mathematical analysis of VSC is given in Figure 2.

The mathematical analysis of VSC using Kirchhoff's voltage rule in the circuit on the left side (Figure 2a) of Figure 2 is given by the following Eq. (12).

$$
V_{t}-U_{a b c}-R i_{t}-L \frac{d i_{a b c}}{d t}=0
$$

where $V_{t}$ is the instantaneous input voltage of VSC, $U_{t}$ is the output voltage of VSC in AC Converter AC side(output voltage of $\mathrm{VSC}$ ) and $l_{t}$ is the instantaneous current passes via in the resistance $(R)$ and reactance $(L)$ of the network.

Using Clark transformation, the time domain analysis is changed to the $(\alpha, \beta)$ coordination.

$$
\left[\begin{array}{l}
x_{\alpha} \\
x_{\beta}
\end{array}\right]=\frac{2}{3}\left[\begin{array}{ccc}
1 & \cos \frac{2 \pi}{3} & \cos \frac{4 \pi}{3} \\
0 & \sin \frac{2 \pi}{3} & \sin \frac{4 \pi}{3}
\end{array}\right]\left[\begin{array}{l}
x_{a} \\
x_{b} \\
x_{c}
\end{array}\right]
$$
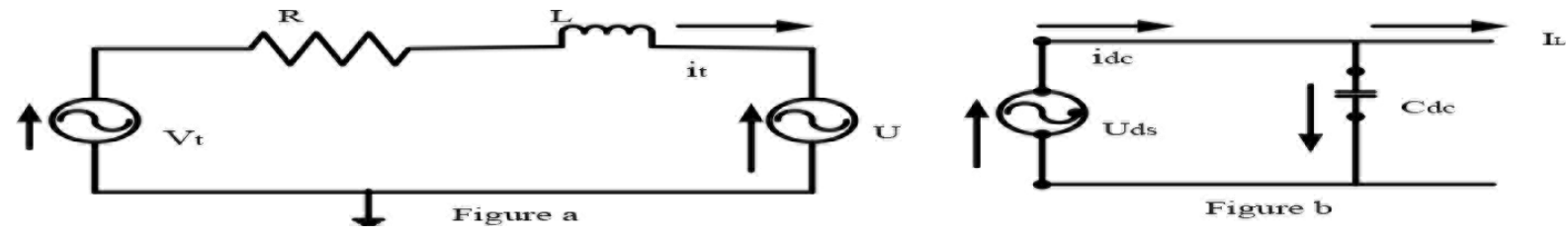

Fig. 2. Equivalent circuit of VSC station. Abbreviation: VSC, voltage source converter 
By using transformation angle from the system phase measurement at the phase lock loop (PLL), the electrical quantities are further transformed from the $(\alpha, \beta)$ stationary coordinate system quantities to rotational $d-q$ reference frame equivalent quantities. By applying park transformation, the electrical parameters are converted to $d-q$ reference frame from the alpha and beta $(\alpha, \beta)$ coordination system by using the following Eq. (14).

$$
\left[\begin{array}{l}
x_{d} \\
x_{q}
\end{array}\right]=\left[\begin{array}{cc}
\cos \theta & \sin \theta \\
-\sin \theta & \cos \theta
\end{array}\right]\left[\begin{array}{l}
x_{\alpha} \\
x_{\beta}
\end{array}\right]
$$

Hence, Eq. (12) is transformed to:

$$
L \frac{d i_{d q}}{d t}=V_{d q}-U_{d q}-(R+\omega L) i_{d q}
$$

In Eq. (15), w represents the angular frequency of the AC network at a normal function of the system. For better understanding, Eq. (15) is split into $d$-axis and q-axis structure, respectively, and Eq. (16) is obtained.

$$
\begin{aligned}
& L \frac{d i_{d}}{d t}=V_{d}-U_{d}-(R+j \omega L) i_{d} \\
& L \frac{d i_{q}}{d t}=V_{q}-U_{q}-(R+j \omega L) i_{q}
\end{aligned}
$$

Current through the capacitor is equal to the current received from the VSC which is DC output current $\left(I_{d c}\right)$ minus the DC link current $\left(I_{L}\right)$ and can be calculated by using the Eq. (17).

$$
I_{\text {cap }}=C_{\mathrm{DC}} \frac{d U_{d c}}{d t}=i_{d c}-i_{L}
$$

where $C_{D C}$ is the capacitance value of the capacitor.

The incoming power to the VSC (ac side power, $P_{a c}$ ) and its output power (dc side power, $P_{d c}$ ) can be expressed by using the Eq. (18).

$$
P_{d c}=\frac{3}{2} V_{d} i_{d}+\frac{3}{2} V_{d} i_{q}=U_{d c} i_{d c}
$$

Since the $d$-axis rotating frame is in phase with the ac voltage side and the $q$-axis rotating frame is quadrature to the ac voltage side, then $V_{q}=0$. Then the active power supplied to the network is expressed by the Eq. (19).

$$
P_{d c}=1.5 V_{d} * i_{d}=U_{d c} i_{d c}
$$

\subsection{The inner current control loop}

The current controller uses the setpoint current from the external controller and $d-q$ changed currents from the transducers. This interior current controller system is made from proportional integrator (a variant) for both $d$ and $q$ axis currents. The main function of the controller changes the error current which is the difference between the actual current and the reference current to a form of the voltage signal. Then this error signal is used by PWM generator to operate VSC as shown in Figure 3.

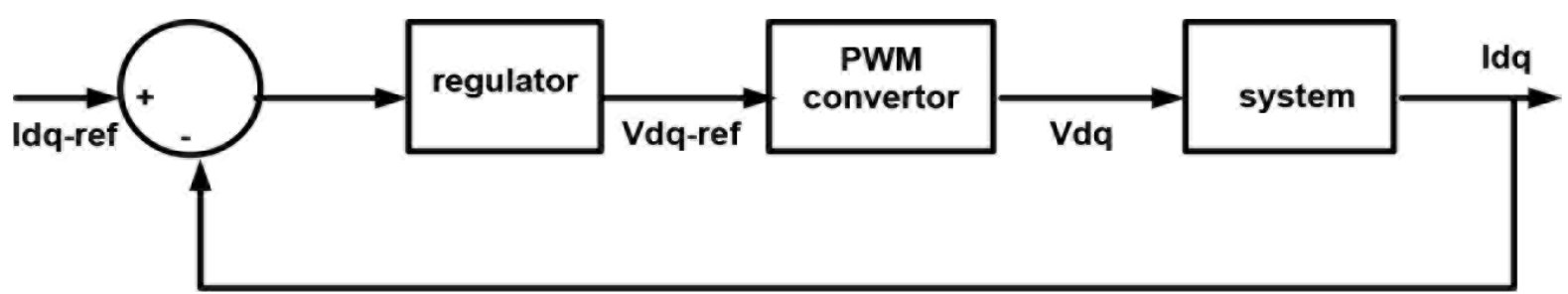

Fig. 3. Inner current control loop. 


\subsection{PI regulator}

The proportional integrator used for the reduction of steady state error to zero can be designed by using Eq. (20).

$$
K_{p}\left(1+\frac{1}{s \mathrm{~T}_{i}}\right)
$$

where $K_{p}$ is proportional gain and $T_{i}$ is the integral time constant. The output voltage signal of the interior controller is given by:

$$
\left(i_{d q}{ }^{*}(s)-i_{d q}\right)\left(K_{p}\left(1+\frac{1}{s T_{i}}\right)\right)=u_{d q}{ }^{*}(s)
$$

\subsection{PWM converter}

The voltage supplies along with the converter sideways by PWM converter is given by:

$$
u_{d q}^{*}\left(\frac{1}{\left(1+T_{a} s\right.}\right)=u_{d q}
$$

where $T_{\alpha}=0.5 T_{\text {switch }}=0.5\left(7.14^{*} e^{-4}\right)=3.57 e^{-4}$ s.

When PWM operation frequency is greater than fundamental frequency $(1400 \mathrm{~Hz})$, then time delay, Ta, equals to $0.000357 \mathrm{~s}$.

\subsection{System transfer equation}

Equation (16) evidences that the $d q$ representation of $A C$ side of the converter system consists of a cross-coupling term $j \omega L i_{d q}$ which is considered as a disturbance for each axis based on the control point perspective. To nullify the cross-coupling (disturbances), compensation terms $V_{d}$ and $\omega i_{q}$ are added to the $d$-axis controller while $V_{q}$ and $\omega l i_{d}$ are added the $q$-axis controller (Pawar et al., 2015). Considering the compensation terms used for decoupling, now the converter input from the controller is:

$$
\begin{aligned}
& u_{d}^{r e f}=-\left(i_{d}^{r e f}-i_{d}\right)\left(K_{p}\left(1+\frac{1}{s T_{i}}\right)\right)+\omega L i_{q}+v_{d} \\
& u_{q}^{r e f}=-\left(i_{q}^{r e f}-i_{q}\right)\left(K_{p}\left(1+\frac{1}{s T_{i}}\right)\right)-\omega L i_{d}+v_{q}
\end{aligned}
$$

where $U_{d}^{\text {ref }}$ is $d$-axis reference voltage, $i_{d}^{\text {ref }}$ is $d$-axis reference current, $U_{q}^{\text {ref }}$ is $q$-axis reference voltage and $i_{q}^{\text {ref }}$ is $q$-axis reference current.

Therefore the converter output is:

$$
\begin{aligned}
& \left(-\left(i_{d}{ }^{r e f}(s)-i_{d}\right)\left(k_{p}\left(1+\frac{1}{s T_{i}}\right)+j \omega L i_{q}+v_{d}\right)\left(\frac{1}{1+T_{a} s}\right)=u_{d}(s)\right. \\
& \left(-\left(i_{q}^{r e f}(s)-i_{q}\right)\left(k_{q}\left(1+\frac{1}{s T_{i}}\right)-j \omega L i_{d}+v_{q}\right)\left(\frac{1}{1+T_{a} s}\right)=u_{q}(s)\right.
\end{aligned}
$$

The converter is assumed as ideal transformer and it has only a time delay impact on its input. Hence, we can assume that the input of the converter is the same as the output except time delay. Substituting Eq. (16) into (24) in time domain results in the following equation.

$$
u_{d}=L \frac{d i_{d}}{d t}+R i_{d} \text { and } u_{q}=L \frac{d i_{q}}{d t}+R i_{q}
$$

It is evident from the Eq. (25) that the cross-coupling terms are eliminated and it is possible now to have independent control of the $d$ and q component currents. Laplace's transformation of Eq. (25) leads us to: 


$$
i_{d q}(s)=\frac{1}{R+L s} u_{d q}(s)
$$

Therefore the system transfer equation will become:

$$
G(s)=\frac{1}{R} \frac{1}{1+s \tau}
$$

$\tau$ is the reactor time constant defined by:

$$
\tau=\frac{L}{R}
$$

\subsection{DC-voltage controller}

Bearing in mind that the converter losses are negligible, then incoming and outgoing power of the converter will be the same, and calculated by using the Eq. (29).

$$
\frac{3}{2} V_{d} i_{d}=V_{d c} * I_{d c}
$$

$\mathrm{DC}, I_{d c}$ can be solved by the following equation:

$$
I_{d c}=I_{L}+C_{d c} \frac{d U_{d c}}{d t}
$$

By using Eqs (29) and (30), the relation between the DC voltage and other factors are given by the following equation which can be used for solving for $U_{d c}$ :

$$
U_{d c}=\frac{1}{C s}\left(\frac{3}{2} \frac{V_{d} i_{d}}{V_{d c}}-i_{L}\right)
$$

\subsection{AC-voltage regulator}

The main function of the AC voltage regulator is to manage the transfer of the reactive power at joint load buses.

The Matlab/Simulink modelling of DSTATCOM is based on the mathematical analysis of device, DSTATCOM, and is presented in Figure 4. It consists of VSC, Direct Current-link capacitor, LCL filters, coupling transformer and control units.

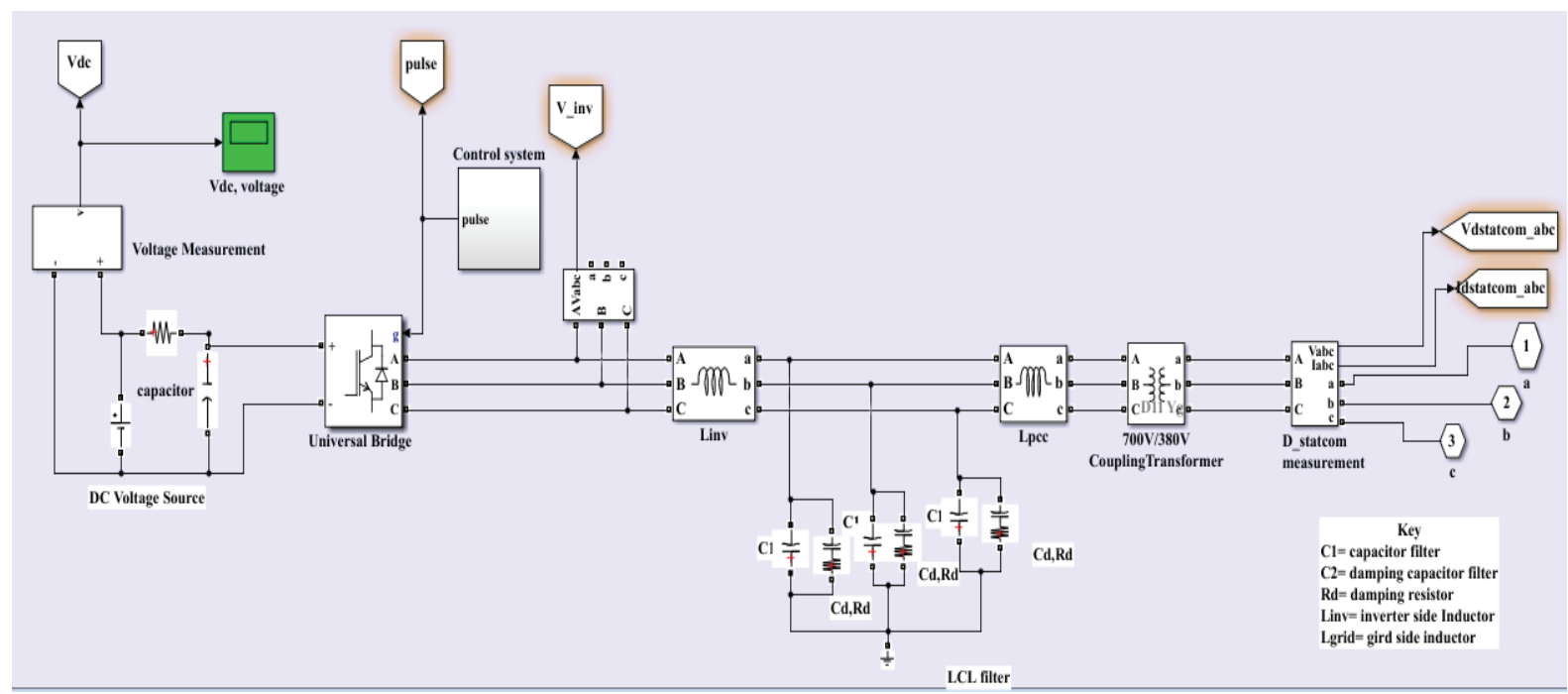

Fig. 4. Configuration of DSTATCOM using Matlab/Simulink. Abbreviation: DSTATCOM, distribution static compensator. 


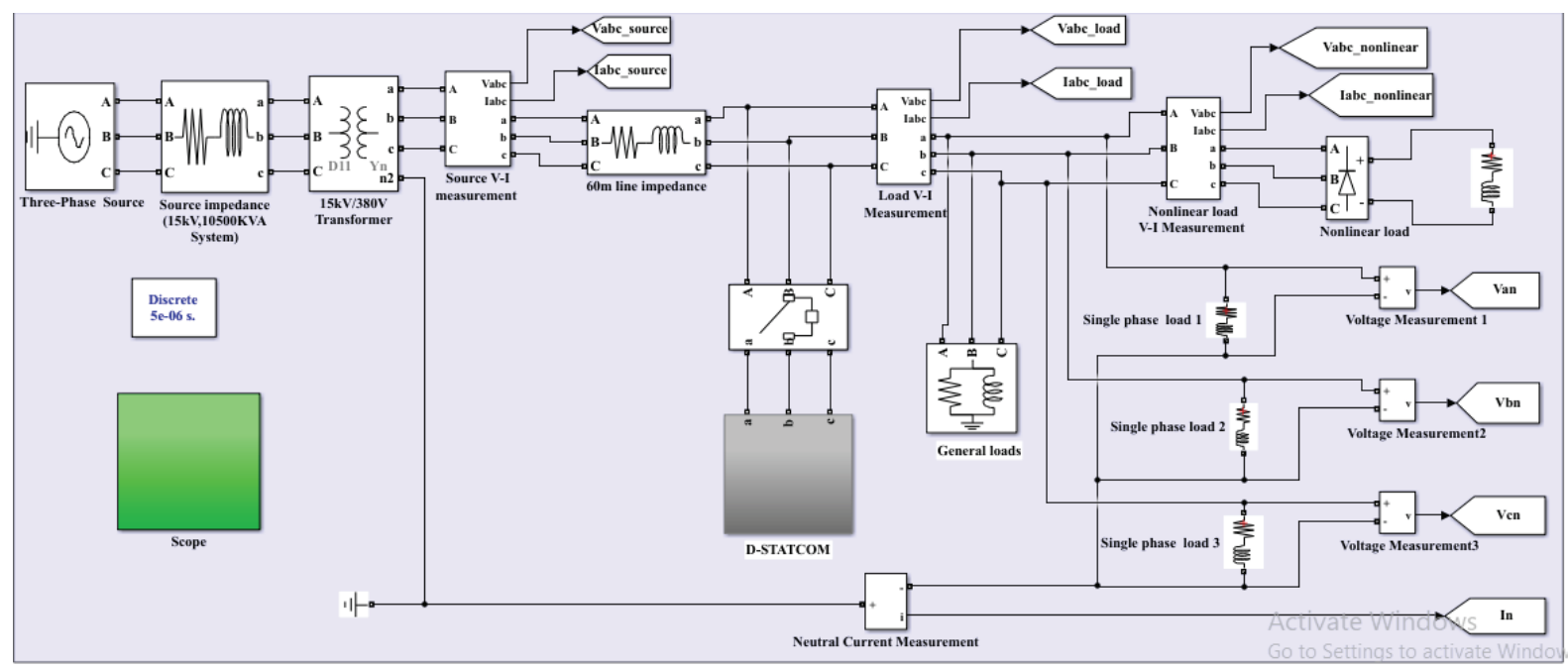

Fig. 5. The entire system of Matlab/Simulink modelling.

\section{Modelling of the Whole System Using Matlab}

Based on the mathematical analysis of the system parameters, the entire system modelling using Matlab consists of three-phase voltage source with external source impedance, system frequency, three-phase transformer, the length between the load terminals or electrical load bus and transformer secondary side. DSTATCOM modelling is done between the load and the source bus. At the connection of load bus and source bus, exchange of reactive power takes place between the DSTATCOM and the original system. The entire system Matlab/Simulink model is shown in Figure 5.

\section{Simulation Results and Discussion Without DSTATCOM}

Figure 6 illustrates the profile of load voltage and load currents. Load voltage magnitudes are around 0.9 p.u value and source voltage profile is same as load voltage profile since there is no change in the original system at this moment. Both source and load current waveforms are distorted and identical. This happens because of high reactive power consumption due to the nonlinear loads, and the inductive loads found in the system. In the nonlinear loads, high distortion of waveform is observed than linear loads as shown in Figure 7. The waveforms of the nonlinear loads are highly distorted due to their rectified characteristics. The effects of waveform distortions or harmonics and deviation from nominal values of voltages and currents in the system result in the increase of transformer and machines heating leading to improper use of electrical energy and also reduce the performance of the system.

Figures 8 and 9 show that the total load power is the same as the total power supply. The total supply power is $448 \mathrm{~kW}$ and $442 \mathrm{kVAr}$. It is observed that there is a highly reactive power consumption from Figure 9 . Reactive power consumption is due to the inductive loads.

\subsection{Total harmonic distortion}

It is observed from the Figure 10, the source and general loads voltages THD is identical which is 3.38\%, and THD of the load current is $6.39 \%$ causing the THD of the source currents to be identical, and it is shown in Figure 11. The THD found in the system has a component of fractional frequency, which is due to the interharmonic and noise signals.

As illustrated in Figures 12 and 13, THD of nonlinear loads of voltage and current are $13.84 \%$ and $22.28 \%$, respectively. 


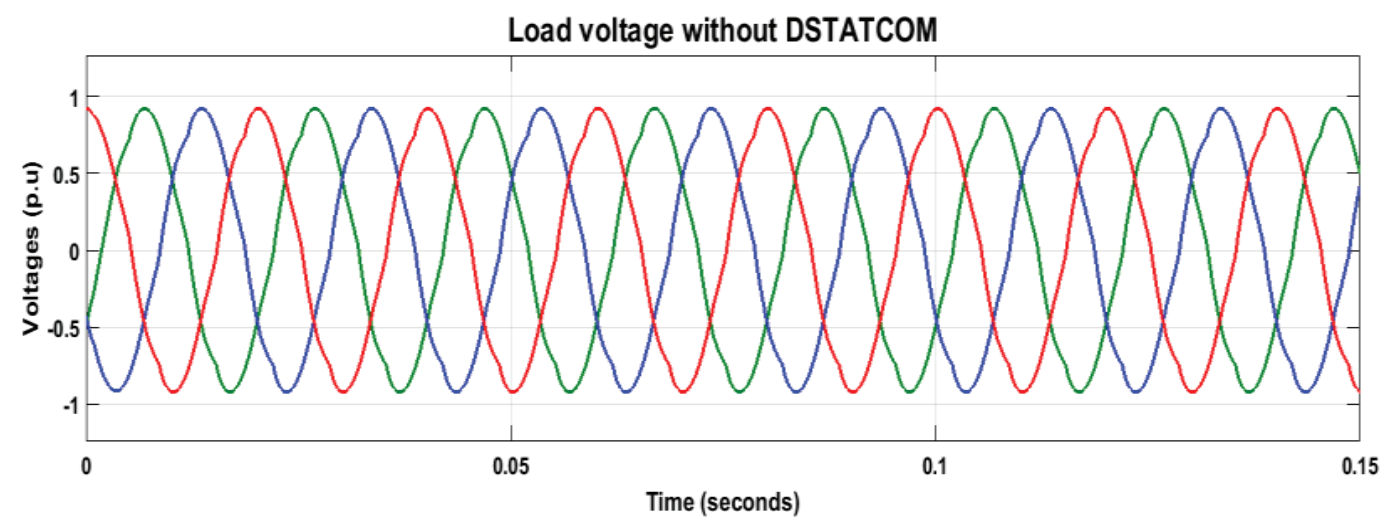

Load current without DSTATCOM

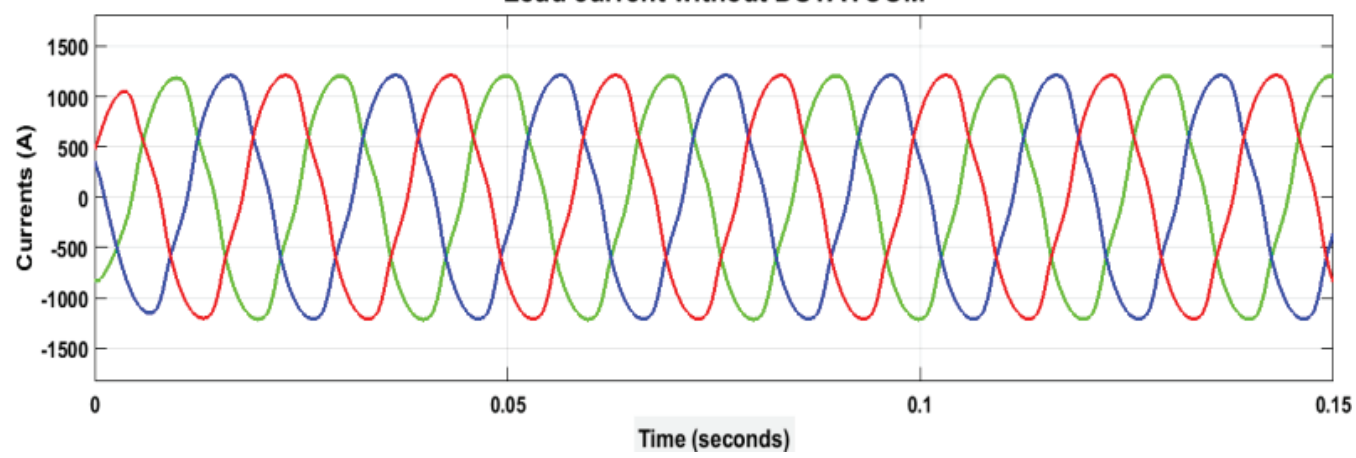

Fig. 6. General load voltages and currents before DSTATCOM is connected. Abbreviation: DSTATCOM, distribution static compensator.
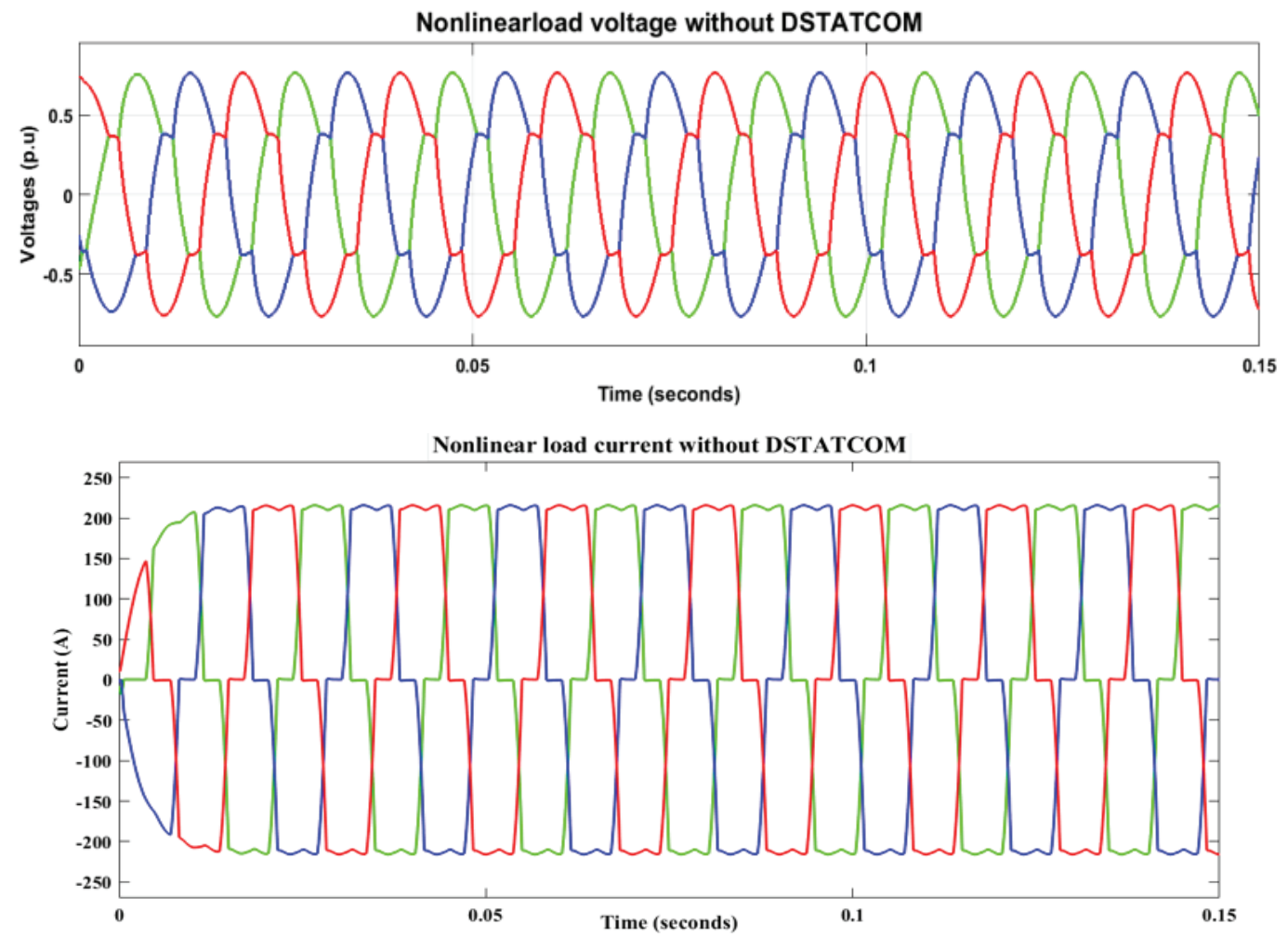

Fig. 7. Nonlinear load voltage and current waveforms before DSTATCOM is applied. Abbreviation: DSTATCOM, distribution static compensator. 

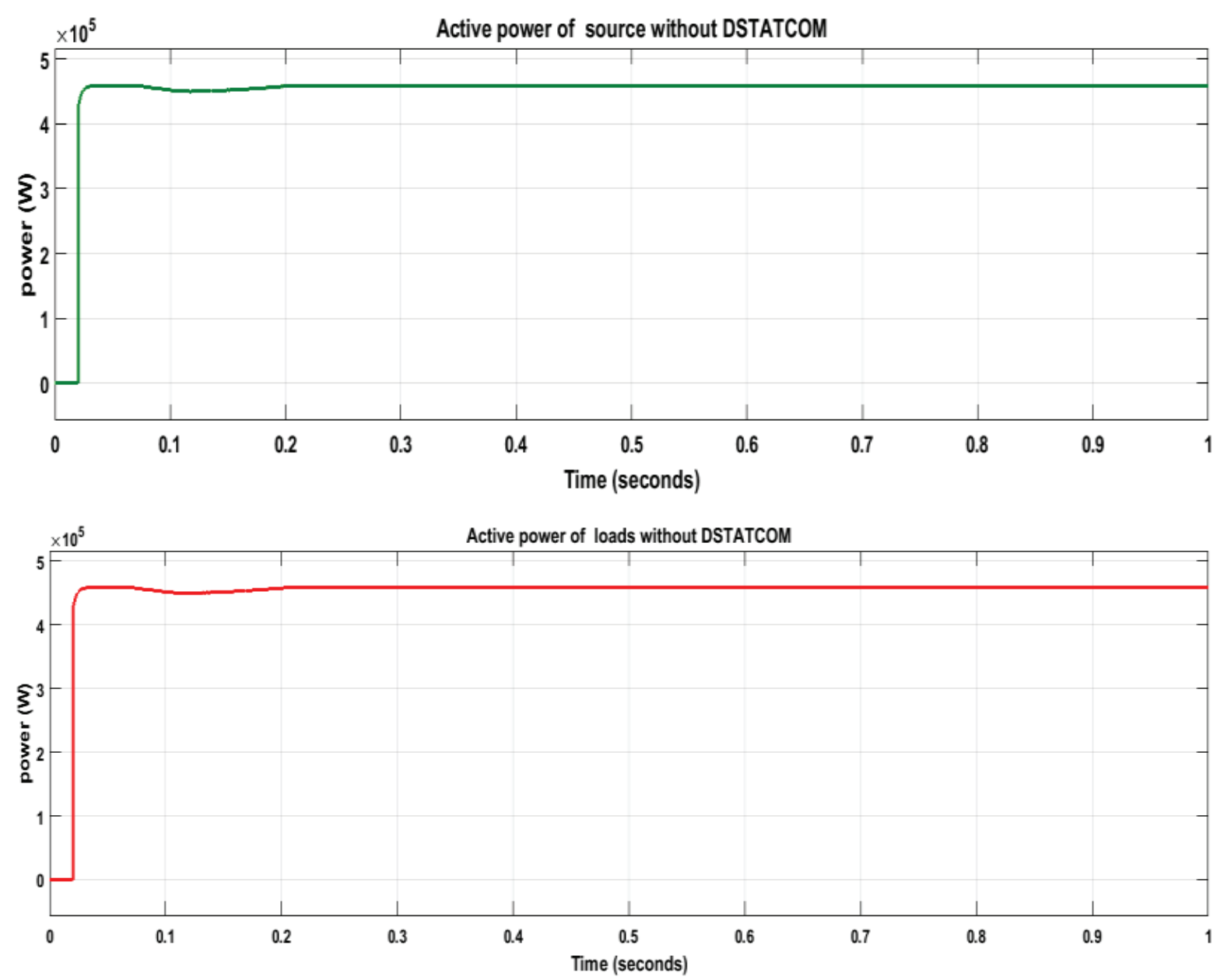

Fig. 8. Active power of the system without the DSTATCOM. Abbreviation: DSTATCOM, distribution static compensator.
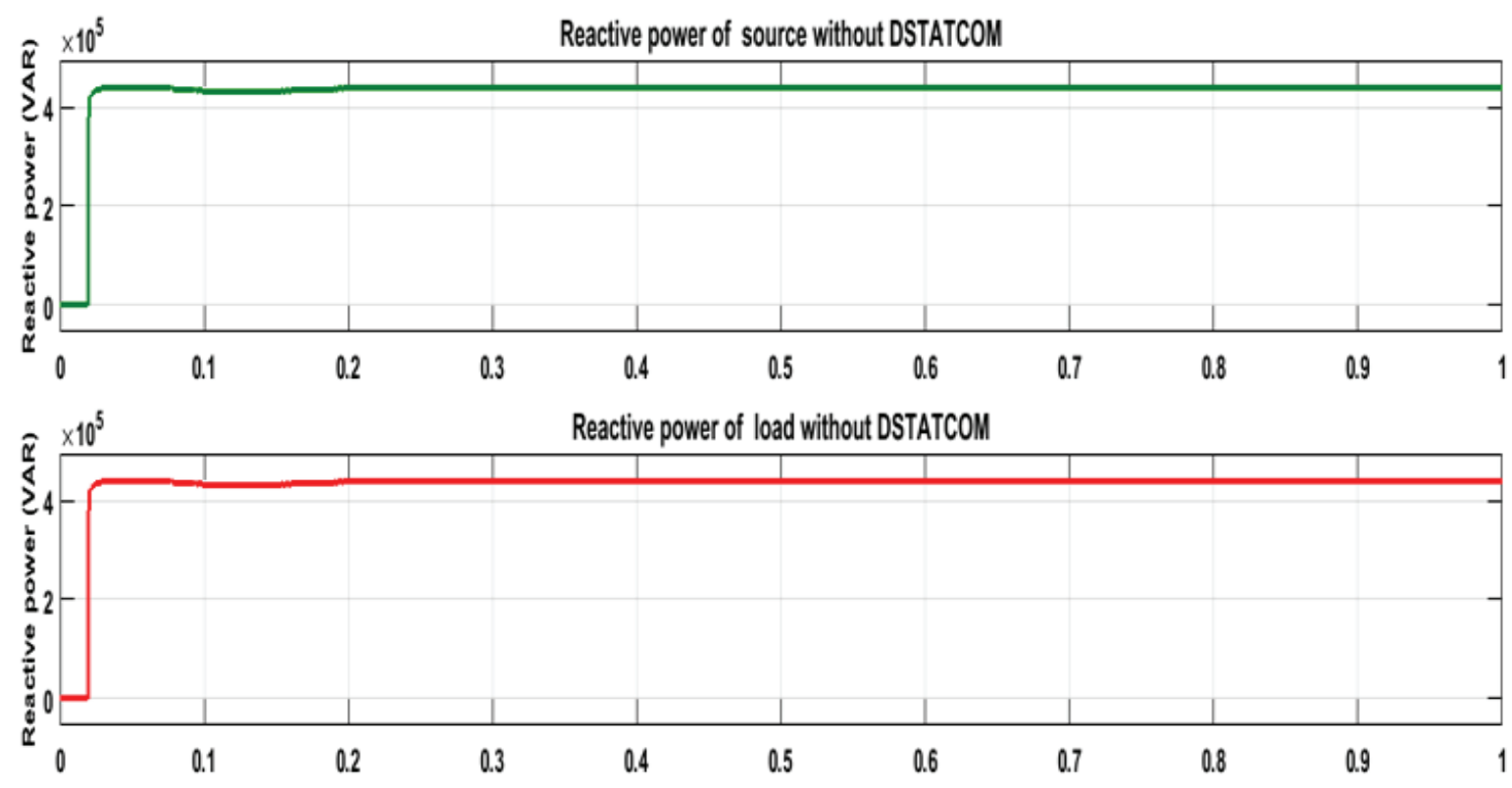

Fig. 9. Reactive power of the system without the DSTATCOM. Abbreviation: DSTATCOM, distribution static compensator. 


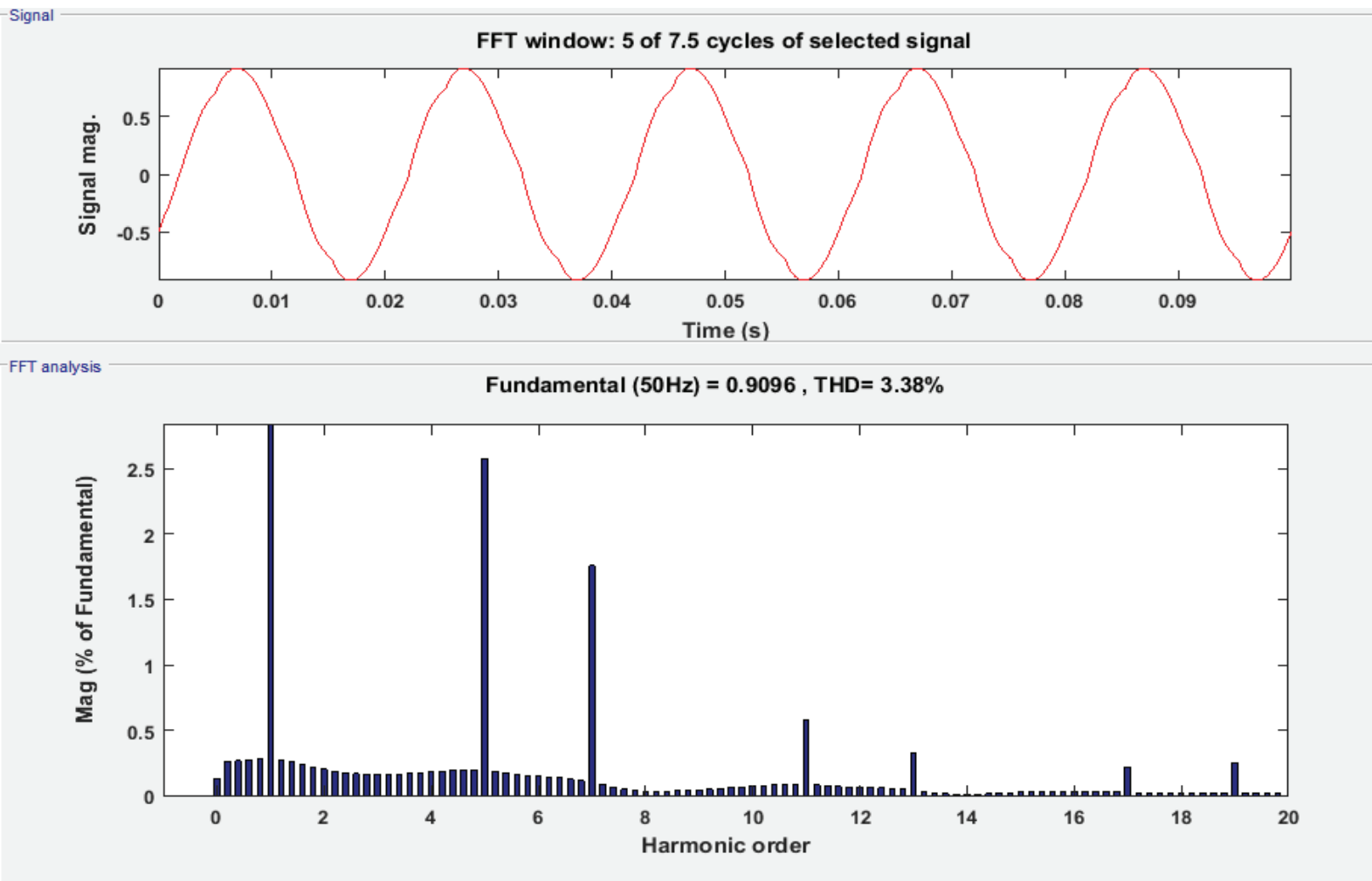

Fig. 10. THD of source voltages without the DSTATCOM. Abbreviations: DSTATCOM, distribution static compensator; THD, total harmonic distortion.

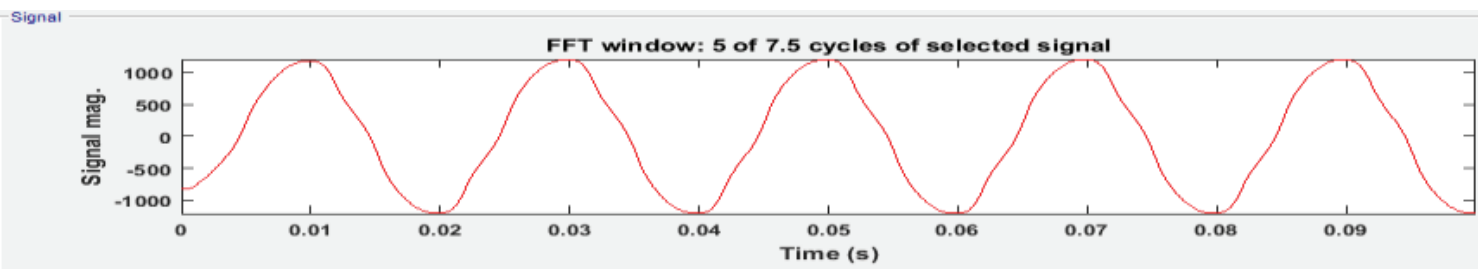

FFT analysis

Fundamental $(50 \mathrm{~Hz})=1210, \mathrm{THD}=6.39 \%$

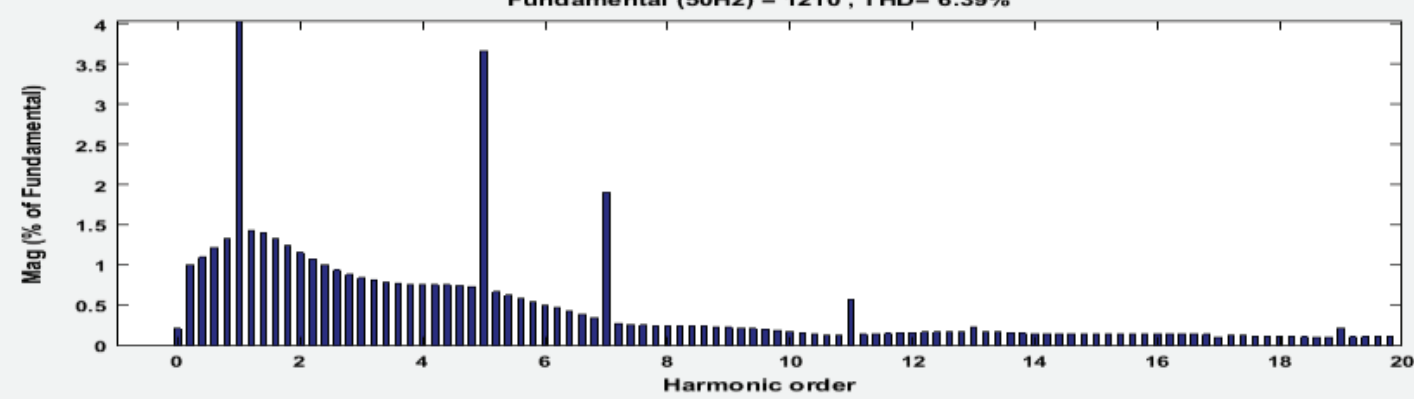

Fig. 11. THD of source currents without the DSTATCOM. Abbreviations: DSTATCOM, distribution static compensator; THD, total harmonic distortion. 


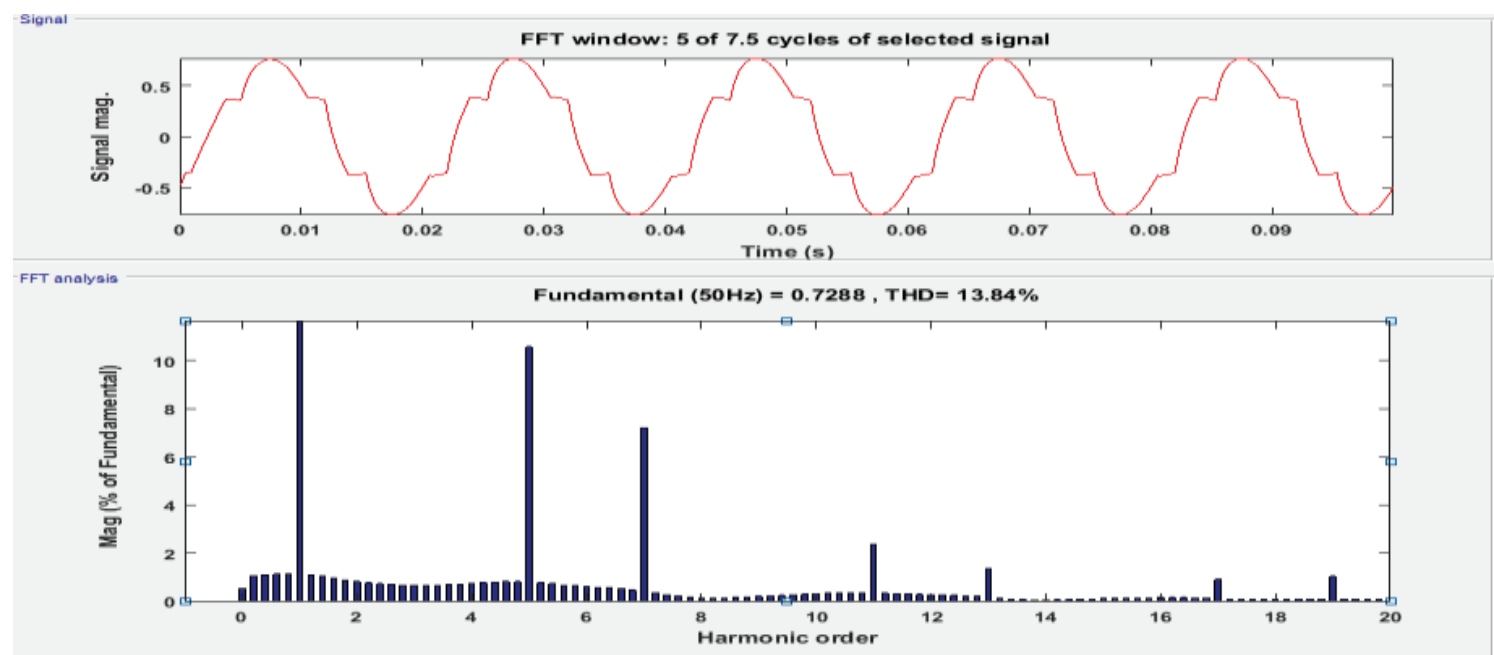

Fig. 12. THD of nonlinear load voltage without the DSTATCOM. Abbreviations: DSTATCOM, distribution static compensator; THD, total harmonic distortion.

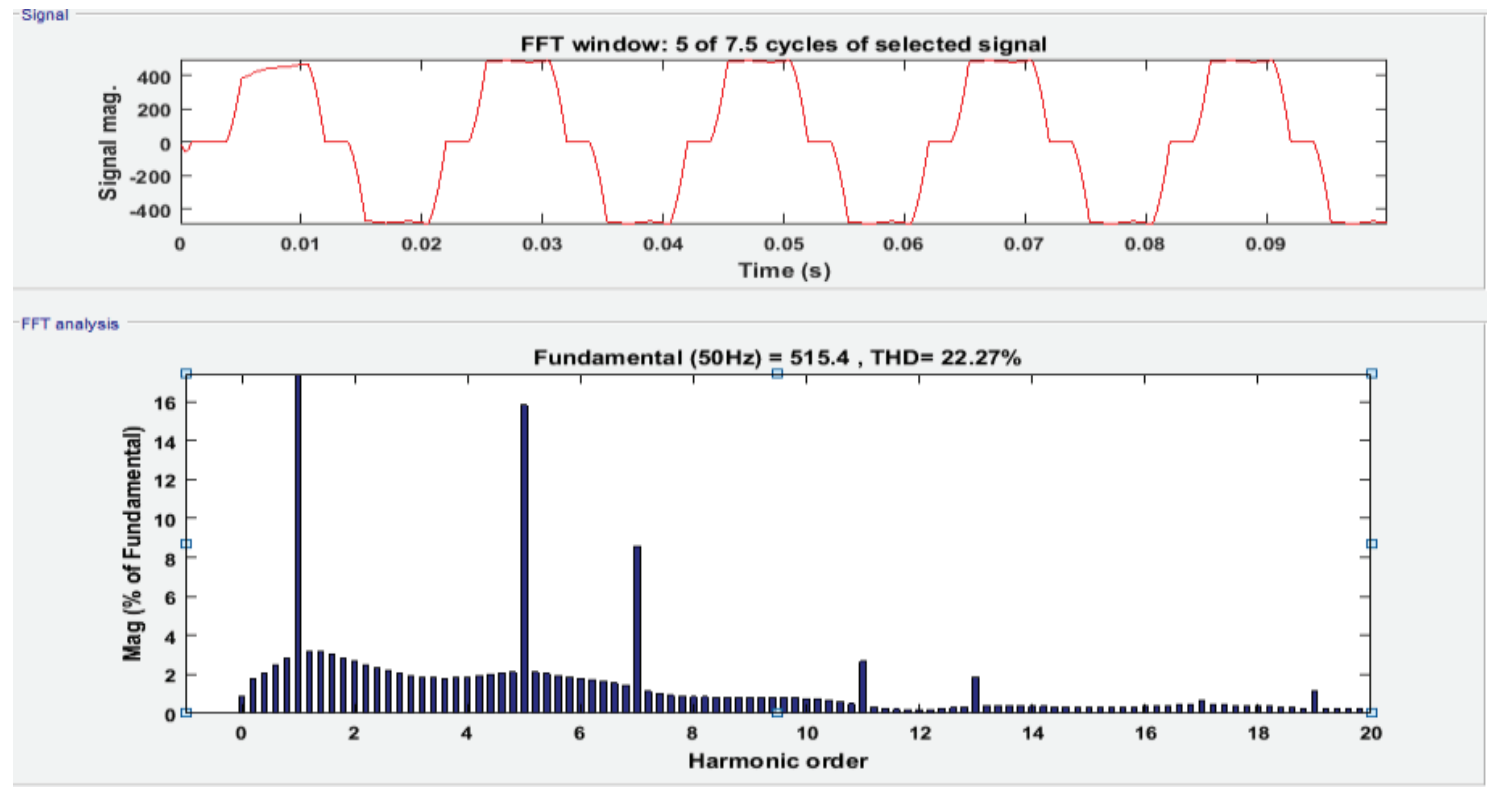

Fig. 13. THD of nonlinear load currents without the DSTATCOM. Abbreviations: DSTATCOM, distribution static compensator; THD, total harmonic distortion.

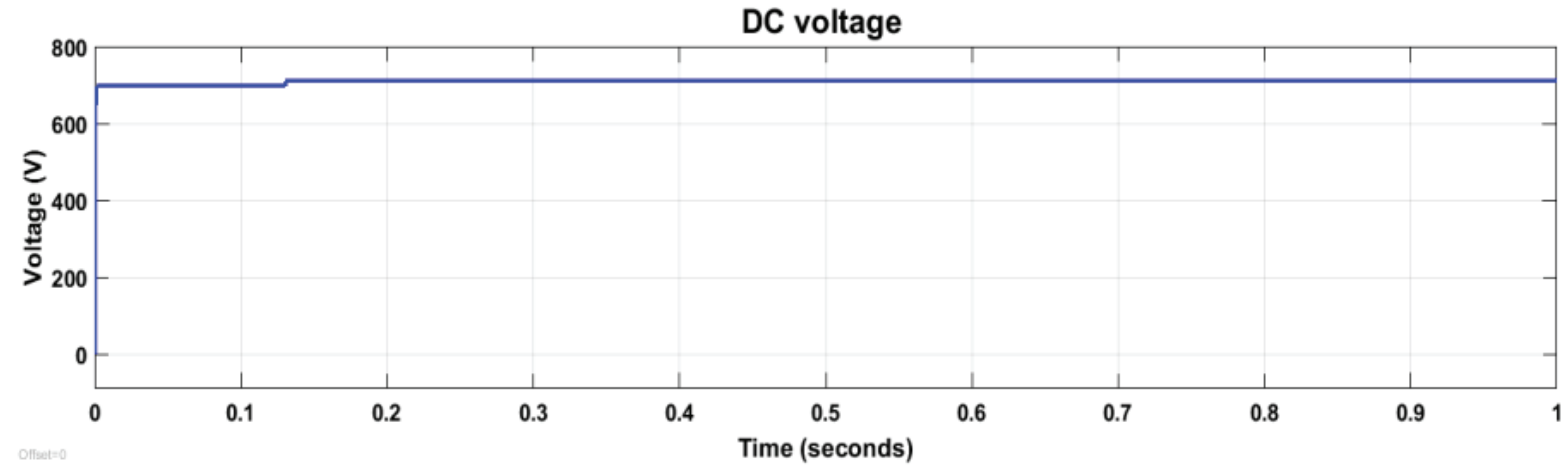

Fig. 14. The DC voltage required at the DC-link capacitor. 


\section{System Simulation Results With DSTATCOM}

The DC voltage required at the DC-link capacitor is set as $700 \mathrm{~V}$ as shown in Figure 14.

In the simulated output waveform, it is observed that the load voltage waveforms are more sinusoidal when compared to the shape of the wave without the DSTATCOM. The voltage profile is increased to $0.9908 \mathrm{p} . u$ and it almost tends towards unity. The wave shape of load currents is more or less not changed when compared to the waveform without the DSTATCOM as expected and Figure 15 illustrates that.

Figure 16 shows that source currents wave shape become more sinusoidal than obtained with the original values from the simulation without DSTATCOM.

From the simulated output waveform, we observe that the nonlinear load voltage waveforms are more sinusoidal when compared to the shape of the wave without the DSTATCOM. This voltage profile is increased to $0.98 \mathrm{p.u}$ as shown in Figure 17. The nonlinear load currents waveform is more distorted than the waveform without the DSTATCOM as illustrated in Figure 17. The interchange here shows that the mitigation device (DSTATCOM) can minimise the disturbances occurring between the nonlinear load bus and the sources bus. Due to this reason, the source current wave shape is more sinusoidal and the nonlinear load current wave shape with DSTATCOM is more distorted than without DSTATCOM.
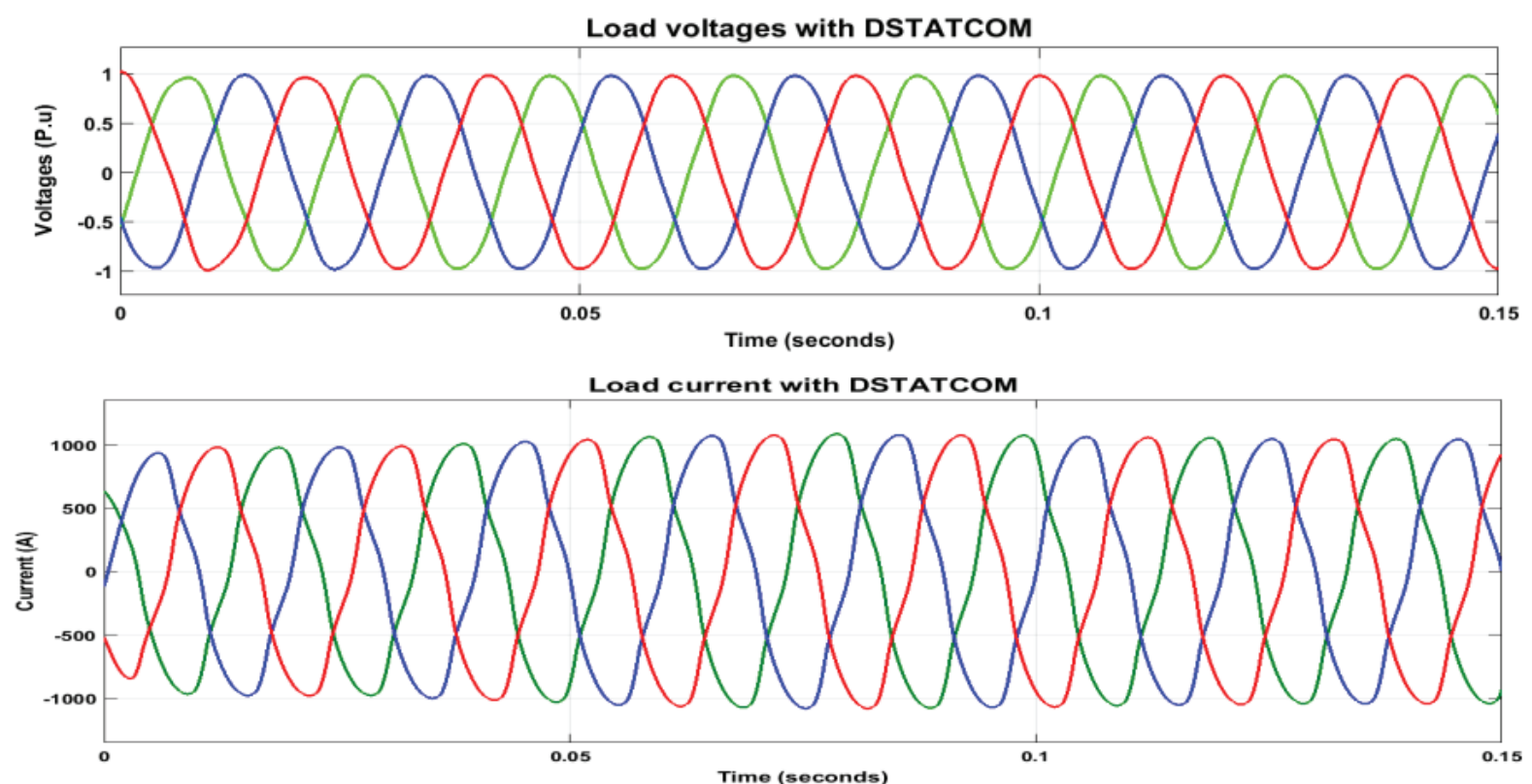

Fig. 15. Load voltages and currents with DSTATCOM. Abbreviation: DSTATCOM, distribution static compensator.

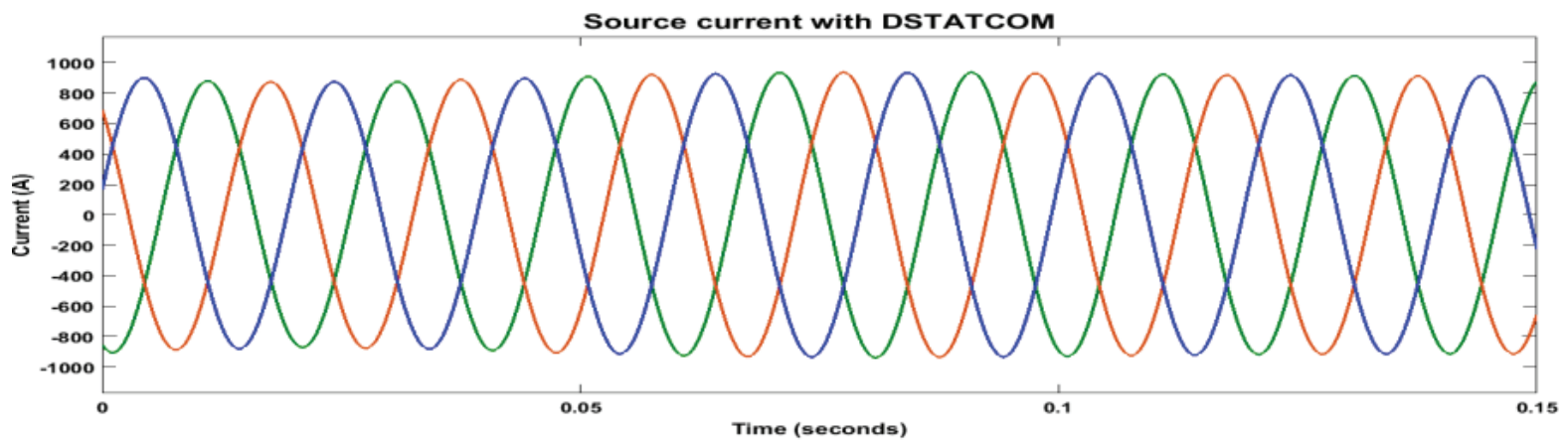

Fig. 16. Source currents with DSTATCOM. Abbreviation: DSTATCOM, distribution static compensator. 

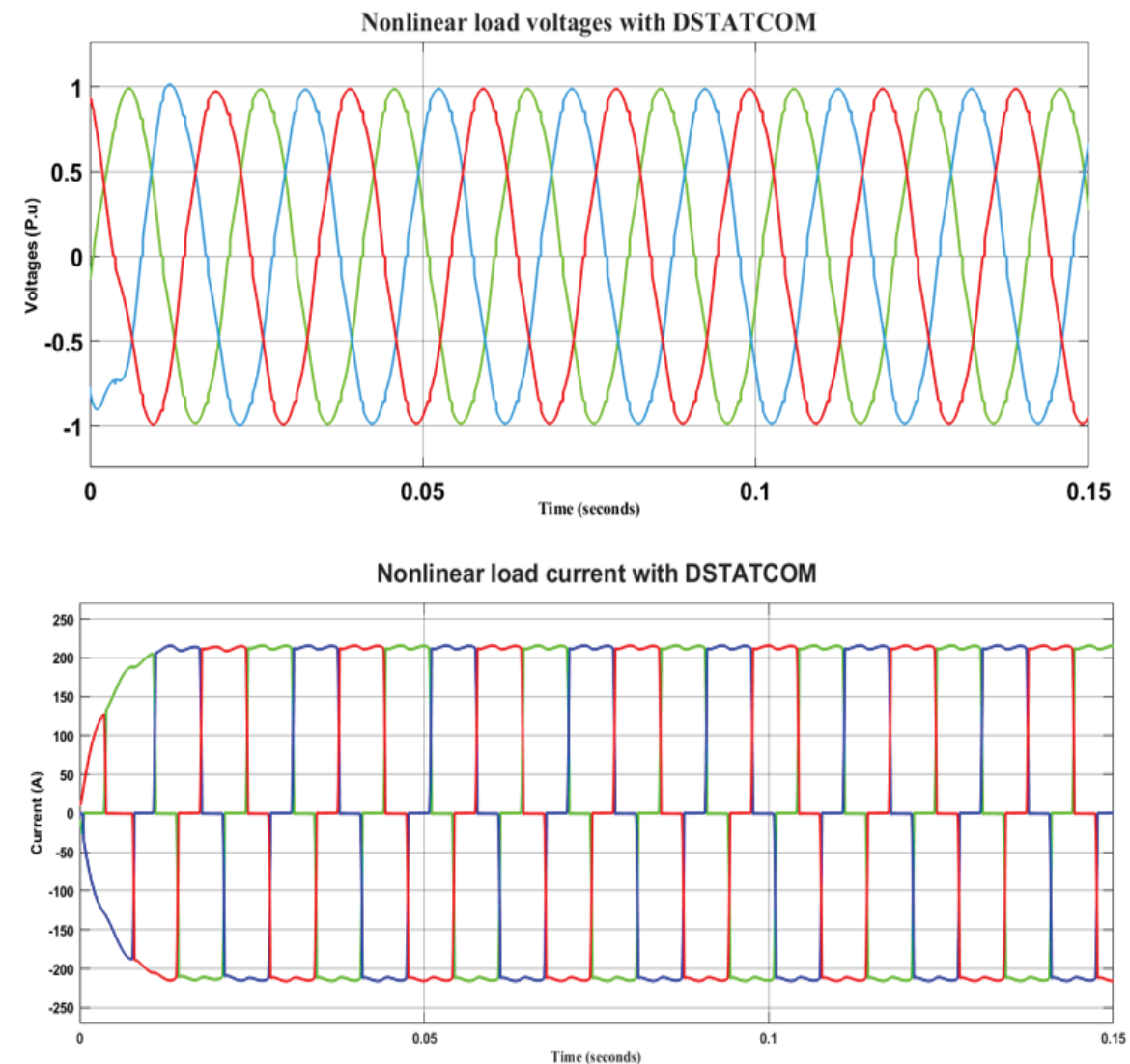

Fig. 17. Nonlinear load voltages and currents waveforms with DSTATCOM. Abbreviation: DSTATCOM, distribution static compensator.
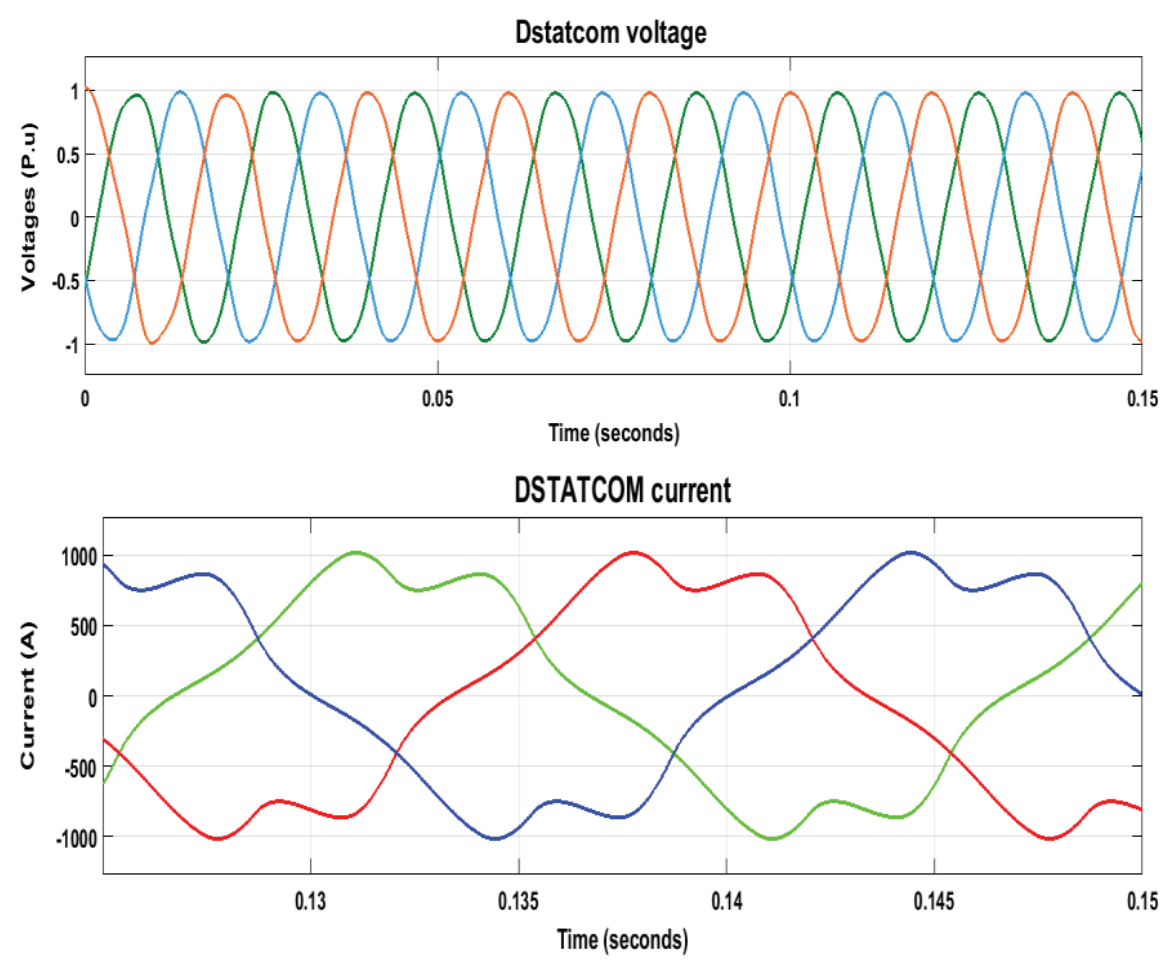

Fig. 18. DSTATCOM voltages and currents. Abbreviation: DSTATCOM, distribution static compensator. 
The DSTATCOM voltages and currents are displayed in Figure 18. The voltage of the DSTATCOM is the same as the load voltage because the measurement is done at the same point. The output current of the DSTATCOM waveform is distorted since the DSTATCOM minimises the disturbances from the load sides and ensures that the source current waveforms are not changed due to the disturbances from the load sides.

As illustrated in Figure 19, DSTATCOM supplies reactive power to the system whenever necessary, and so the source voltages and source currents profiles are improved resulting in waveform of source voltages to be more sinusoidal than in the case without the connection of DSTATCOM. The load reactive power consumption is 442 kVAr and the total reactive power supply by the DSTATCOM is $420 \mathrm{kVAr}$ while the source bus reactive power supply becomes minimised and its contribution is only $22 \mathrm{kVAr}$. The lagging power factor of the source bus is increased from 0.7125 to 0.999 and it tends to unity. It is found from Figure 19 that reactive power consumption from the source bus is reduced to $22 \mathrm{kVAr}$.

As shown in Figure 20, THD of both the source voltage and load voltage is reduced to $1.55 \%$, which is identical with THD of the source voltage. THD level for supply current is observed to be $0.98 \%$ as shown in Figure 21 . The proposed DSTATCOM can compensate the harmonics present in the load current. The THD level of the load current is almost constant.

The voltage waveform of the nonlinear load is improved and its THD of the nonlinear load voltage is reduced to $3.5 \%$ as shown in Figure 22. The THD of nonlinear load currents are increased to $29.5 \%$ and are presented in Figure 23. Increase in the THD of nonlinear load currents illustrates that the proposed DSTATCOM can compensate the harmonics present in the source bus. As presented in Figures 20 and 21, the THD of source currents and voltages are minimised by $5.41 \%$ and $1.83 \%$, respectively.
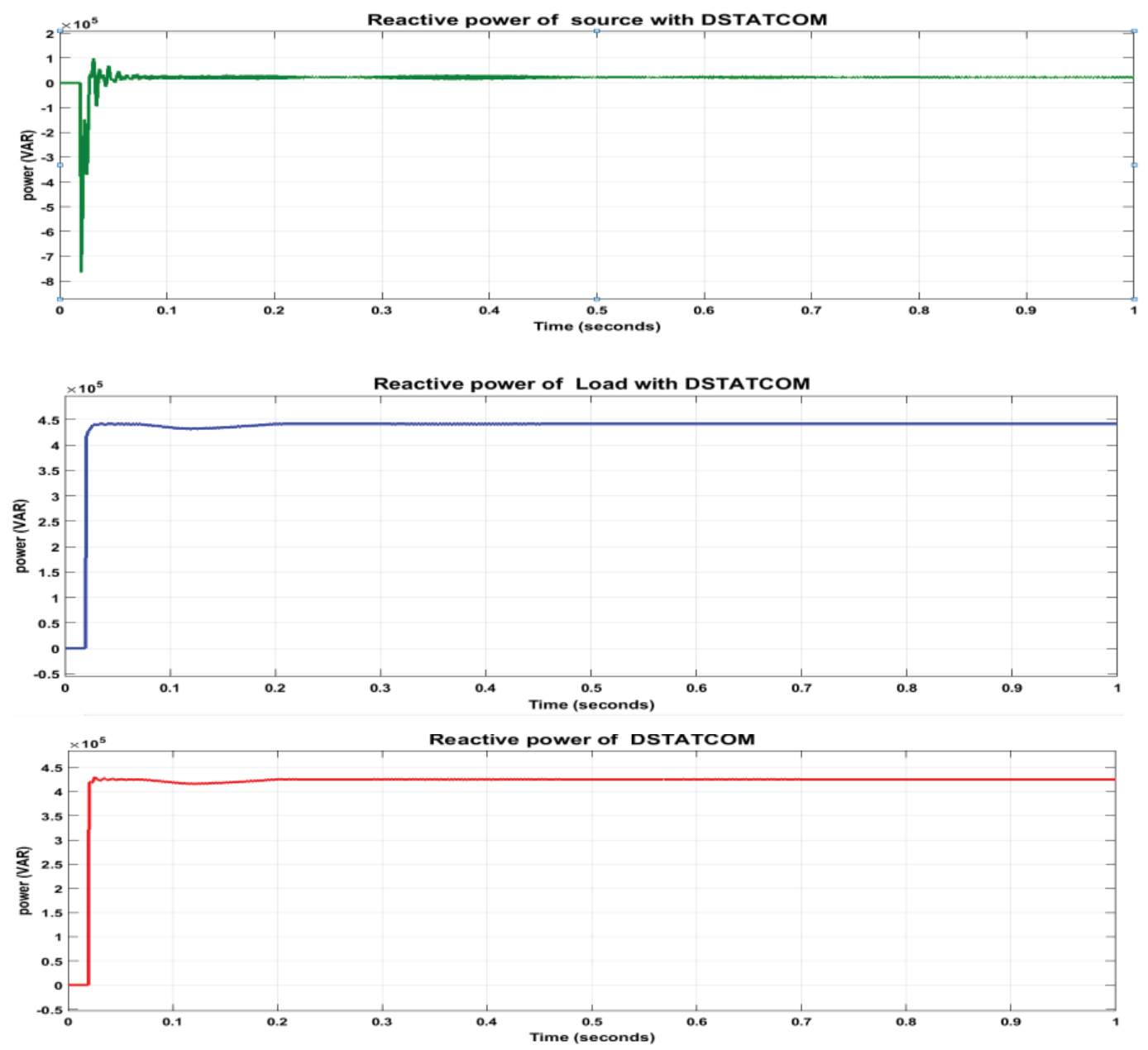

Fig. 19. Reactive power of the system with DSTATCOM. Abbreviation: DSTATCOM, distribution static compensator. 


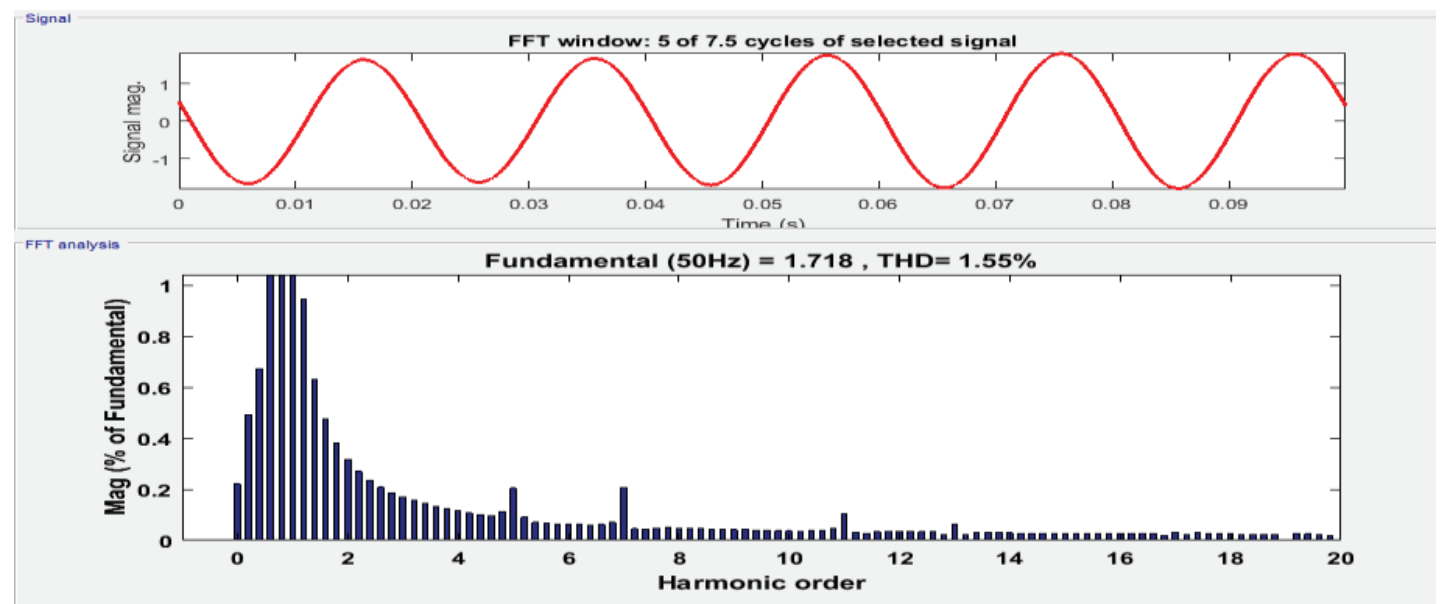

Fig. 20. The THD of the source voltage with DSTATCOM. Abbreviations: DSTATCOM, distribution static compensator; THD, total harmonic distortion.

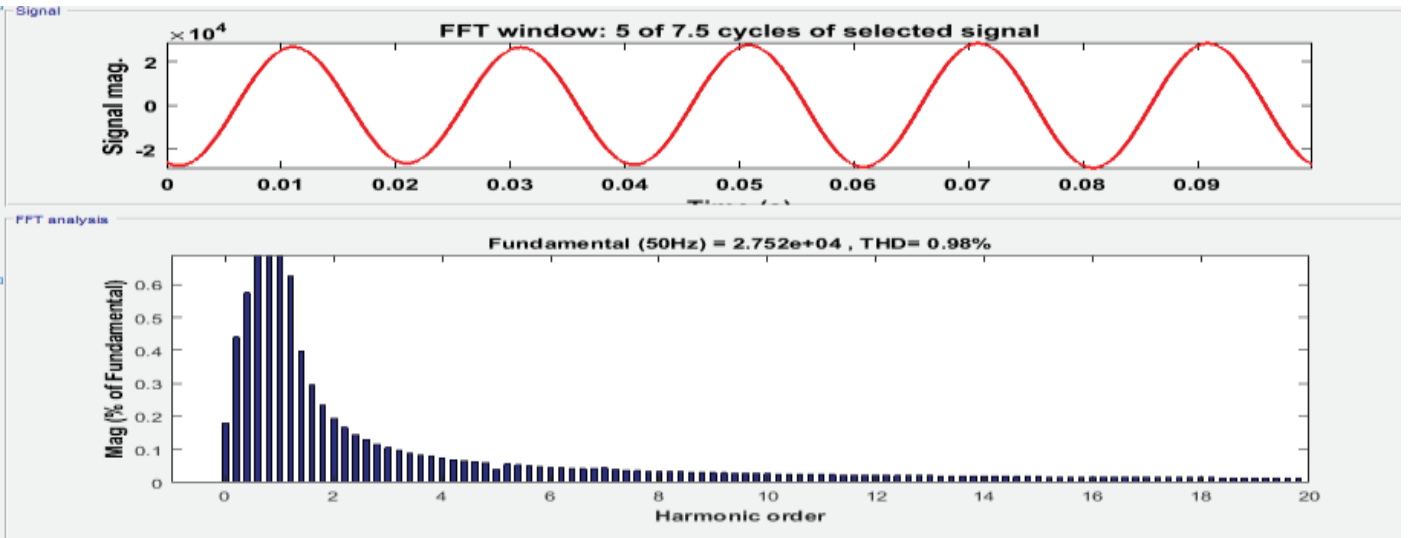

Fig. 21. The THD of the source currents with DSTATCOM. Abbreviations: DSTATCOM, distribution static compensator; THD, total harmonic distortion.

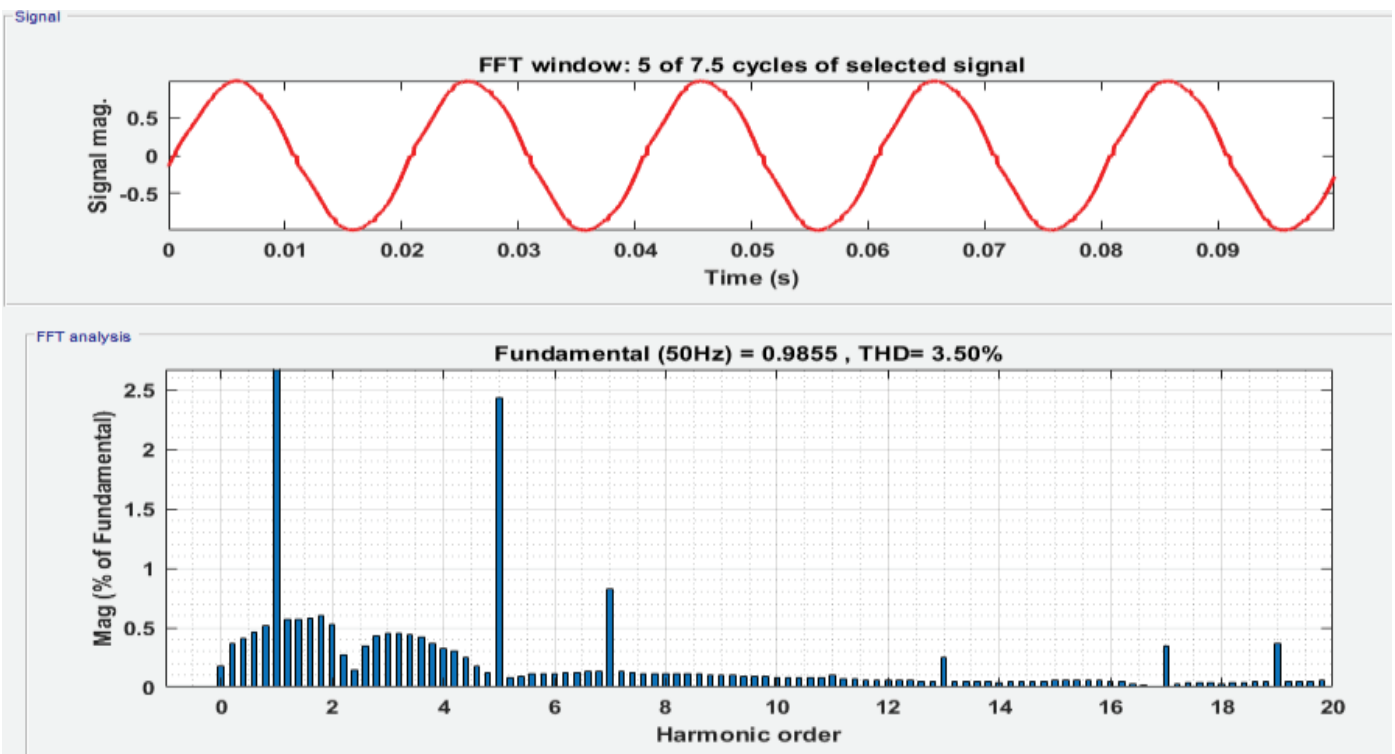

Fig. 22. THD of nonlinear load voltages with DSTATCOM. Abbreviations: DSTATCOM, distribution static compensator; THD, total harmonic distortion. 


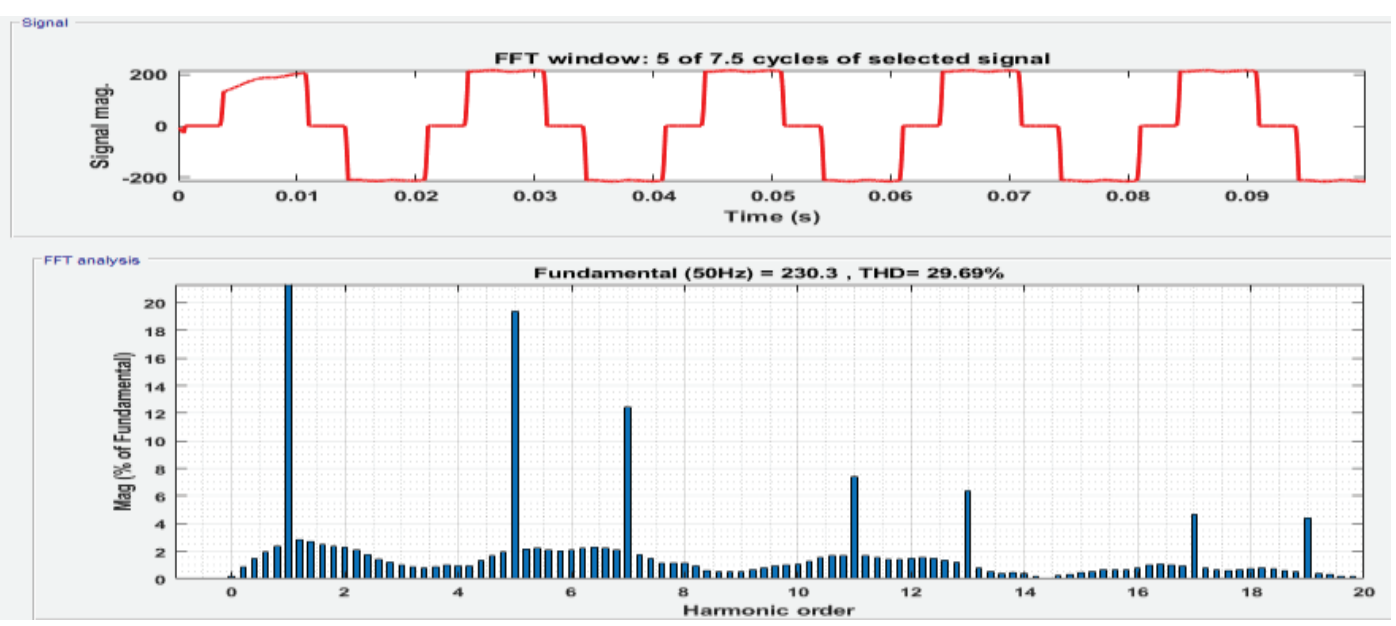

Fig. 23. THD of nonlinear load currents with DSTATCOM. Abbreviations: DSTATCOM, distribution static compensator; THD, total harmonic distortion.

\section{Conclusions}

Based on the data collection and analysis, it is observed that the factory has the following power quality problems such as high reactive power consumption of the supply power as the working power factor is very low, such as 0.7125 and due to this low power factor, the factory pays about 3497.4Birr per month as power factor penalty; THD due to the source voltage, and current of the system is found to be $3.38 \%$ and $6.39 \%$, respectively. The nonlinear loads harmonic distortion of the currents is $22.28 \%$ and voltage THD of the nonlinear loads is $13.84 \%$. Voltage variations up to $9.09 \%$ and the average voltage unbalance $2.2 \%$ are obtained.

After installation of DSTATCOM, the THD of both the load and source voltages are reduced to $1.55 \%$. Source current THD is reduced to $0.98 \%$, the lagging power factor of the supply power is increased to 0.999 . Boosting of power factor is necessary as it reduces the power loss of the system.

\section{References}

Chauhan, R. K. and Pandey, J. P. (2014). Mitigation of Power Quality Problems Using FACTS Devices: A Review. International Journal of Electronic and Electrical Engineering. ISSN 0974-2174, 7(3), pp. 255-262.

Hossain, E., Rıda, M., Sanjeevaikumar, P., Selim, A. and Imtiaz, K. (2018). Analysis and Mitigation of Power Quality Issues in Distributed Generation Systems Using Custom Power Devices, IEEE, DOI 10.1109/ ACCESS.

IEEE. (2012December04). IEEERecommendedPractice for Monitoring Electric Power Quality IEEE Xplore (pp. IEEE Std 1159-1995).

Johnsoy, D. O. and Hagren, K. A. (2016). Issues of Power Quality in Electrical Systems. International Journal of Energy and Power Engineering, 5(4), pp. 148-154.

Kaur, S. (July 2014). Investigating the Role of DSTATCOM In Distribution Network With Non-Linear Load and Active Load. (Master of

Engineering In Power Systems), Thapar University, Patiala-147004.

Mehta, V. K. (2017 September 14). Principles of Power System, ISBN-13 : 978-8121924962, Publisher : Chand (S.) \& Co Ltd ,India.

Nawaz, S. K. G. and Hameed, S. (2013 November). Mitigation of Power Quality Problems by Using $D$-STATCOM. Paper presented at the International Conference on Electrical Electronics and Computer Science-EECS-17th EEE, QCET, Corpus ID: 210173086.

Paramar, M. B. S. and Vora, M. S. M. (2015 May). Investigations on Power Quality Improvement in Distribution Network using DSTATCOM. International Journal for Technological Research in Engineering, 2(9), pp 1840-1846.

Pawar, S. S., Deshpande, A. P., and Meera, M. (2015). Modelling and Simulation of DSTATCOM for Power Quality Improvement in Distribution System Using MATLAB Simulink Tool, International Conference 
on Energy Systems and Applications(2015), Pune, India. IEEE, DOI: 10.1109/ICESA.2015. 7503344.

Praveena, S. \& et al. (2017). Performance of Custom Power Devices for Power Quality Improvement. Paper presented at the IEEE International Conference on Power, Control, Signals and Instrumentation Engineering (ICPCSI-2017, Hyderabad, Telengana, India.

Priyanka, S. Sunitha, R. et al (2017). Power Quality Improvement in Power Distribution System using D-STATCOM. IJESC, 7(6), pp. 13298-13302.

Reid, W. E. (2016 June). Power Quality IssuesStandards and Guidelines. IEEE Transactions on Industry Applications, 32(3, pp 625-632.

Saradva, P. M., Kadivar, K. T., Pamdya, M. H., and Rana, A. J. (2016). Application of D-STATCOM to Control Power Flow in Distribution Line. IEEE, Nagercoil, India, pp. 479-484.

Sedaghati, R., Afroozi, N. M., and Nemati, Y. (Dec 2013). A Survey of Voltage Sags and Voltage Swells Phenomena in Power Quality Problems. IJSRM, 1(9), pp. 458-462.
Shah, S., and Parsa, L. (2016). Impedance Modeling of Three-Phase Voltage Source Converters in DQ, Sequence, and Phasor Domains. IEEE, 32(3), pp. 1139-1150, DOI: 10.1109.

Shahewar, S., Maloth, R. and Sushmalatha, S. (2014 January). Power Quality Issues and their Mitigation Techniques. International Journal of Industrial Electronics and Electrical Engineering, 2(1), pp. 148-154.

Tavakoli Bina, M. and Pashajavid, E. (2009). An Efficient Procedure to Design Passive LCL-Filters for Active Power Filters. Electric Power Systems Research, 79(4), pp. 606-614.

Teke, A., Yolda, Y. and Latran, M. B. (2015 June). Step by Step Design Procedure of a Distribution Static Synchronous Compensator (DSTATCOM). Çukurova University Journal of the Faculty of Engineering and Architecture, 30(1), pp. 117-131.

Xia, Z., Shi, L. and Yang, X. (2014). Parameters design and control strategy of cascade STATCOM based on LCL filter. International Journal of Control and Automation, 7(1), pp. 307-320. 